\title{
A DESCRIPTIVE PROFILE OF ISOMETRIC MUSCLE STRENGTH AND MUSCLE STRENGTH IMBALANCE IN YOUNG TENNIS PLAYERS
}

\author{
Anna Zuša, Jānis Lanka, Lenīds Čupriks, Irēna Dravniece \\ Latvian Academy of Sport Education, Riga, Latvia
}

\begin{abstract}
Background. Tennis is assumed as asymmetric sport, prolonged training practice could affect muscle strength imbalance. Muscle strength functional ratio imbalance could be a reason for poor posture, physical weakness and increased risk of injury. The purpose of the research was to evaluate young tennis players' main muscle group strength topography and to investigate the level of different muscles groups' bi-lateral and contra-lateral imbalance.

Methods. The participants of the study were six young right handed competitive tennis players (girls, age $11.4 \pm$ 0.5 years, tennis experience $4.7 \pm 0.6$ years). Examination of main muscles groups was performed with an isokinetic dynamometer.

Results. Young tennis players have pronounced bi-lateral imbalance between shoulder joint extensors and flexors $(25 \%)$, internal and external rotators $(36 \%)$, left elbow flexors and extensors $(58 \%)$, wrist pronator and supinator (the right hand $17 \%$, left $48 \%$ ), hip flexors and extensors (35\%); knee joint flexors and extensors (60\%); ankle dorsal flexors and plantar flexors (59\%); spine and abdominal muscles (48\%). It was detected that young tennis players have pronounced contra-lateral imbalance between right and left internal rotators of the shoulder joint (27\%) and external rotators (26\%), wrist joint supinators (41\%).

Conclusions. To avoid the increase in muscle bi-lateral imbalance it is highly recommended to pay more attention to shoulder adductors and shoulder external rotators, elbow flexors and extensors, wrist supinators and extensors, knee extensors, ankle plantar flexors and spine flexors. For contra-lateral imbalance prevention in addition to train non-dominant upper extremity muscles: shoulder internal and external rotators, wrist supinators.
\end{abstract}

Keywords: bi-lateral imbalance, contra-lateral imbalance, maximal isometric torque, muscle functional ratio, asymmetry.

\section{INTRODUCTION}

$\mathrm{M}$ uscle strength plays an important role in sports where maximum power should be applied in transitional and fast movements, which are throwing-like movements (Bartonietz, 1994; Clements, Ginn, \& Henley, 2000; Hay, 1992; Henry, 1960; Kopsic Segal, 2002). Tennis player performs about 380 strokes on average during one hour of play. Minimal time spent in trainings is two hours a day, tennis game in competition may last from one to five hours (Girard \& Millet, 2008; Kovacs, 2006). To clarify the winner they have to play at least 48 matches in a game of three sets and 72 matches in a game of five sets (Christmass, Richmond, Cable, \& Arthur, 1998; Mendez-Villanueva, FernandezFernandez, Bishop, Fernandez-Garcia, \& Terrados, 2007). Minimum number of stokes per game may fluctuate from 130 to 220 for which they need as many contractions of working muscles as possible. An ability to withstand great pressure depends on enormous muscle strength and endurance during the whole game, were we can observe a fatigue- 
resistance phenomenon (Stephenson, Lamb, \& Stephenson, 1998). The more powerful stroke is produced, the greater muscle effort is made. Not only wrist, elbow and shoulder joint muscles take part in the stroke generation, but also great input is produced by body core and lower limb muscles (Reid \& Schneiker, 2008). The demands of tennis can lead to characteristic injury patterns and musculoskeletal system adaptation (Ellenbecker, Pluim, Vivier, \& Sniteman, 2009).

The evaluation of young tennis players' muscle strength condition is important because of several points of view. First of all, muscle strength testing helps coaches control proper and harmonic muscle system evaluation and assess physical fitness of an athlete for strength training improvement (Andrade et al., 2013; Reid \& Schneiker, 2008; Ulbricht, Fernandez-Fernandez, \& Ferrauti, 2013; Zuša, 2013). Secondly, knowledge about muscle strength condition and functional ratio between agonistantagonist (bi-lateral imbalance), dominant and non-dominant body side (contra-lateral imbalance) is vital for reducing and predicting the risk of injury because muscle strength imbalance could effect this (Alizadehkhaiyat, Fisher, Kemp, \& Frostick, 2007; Andrade et al., 2013; Ellenbecker, Roetert, Sueyoshi, \& Riewald, 2007; Hayot et al., 2014; Kovacs, 2006; Nagel \& Avram, 2013; Saccol et al., 2010). In spite of common traumas and complains on different joint, back pain in sport, subject of muscle strength imbalance in different age athletes still has been not sufficiently studied (Everett, Strutton, \& McGregor, 2008; Saccol et al., 2010).

The aim of the research was to evaluate young tennis players' main muscle group strength topography and to assess the level of bi-lateral and contra-lateral imbalance. We hypothesized that young tennis players have pronounced muscle strength bi-lateral imbalance between shoulder adductors and abductors, internal and external rotators, wrist supinators and pronators, and contralateral imbalance between dominant and nondominant upper extremities shoulder adductors and internal rotators, wrist flexion, extension and supination muscles strength.

\section{METHODS}

Participants. The participants of the experiment were six healthy and competitive tennis players (girls, age $11.4 \pm 0.5$ years, mass $42.6 \pm$ $4.6 \mathrm{~kg}$, height $157.8 \pm 5.2 \mathrm{~cm}$, tennis experience $4.7 \pm 0.6$ years, weekly training $10 \pm 2$ h). All tennis players were right handed. The research was accepted by Latvian Academy of Sport Education local Ethics Commission (Resolution No. 11-D1).

Testing procedure. An isokinetic device (Rev-9000, Italy) was used for the determination of the maximum isometric torque in selected joint positions in the major muscle groups of young tennis players. The testing procedure was originated based on the recommendations of Davies, Ellenbecker and Brinks (2000). Before testing each participant was encouraged to perform a general 8-10 min warm-up. Maximal muscle strength testing procedure consisted of specific joint warm up of $60 \mathrm{~s}$, followed by $6 \times 3 \mathrm{~s}$ isometric muscle work (fixed joint angular position, with resistance $600 \mathrm{~N} \cdot \mathrm{m}$ and fixed speed at $0 \% \mathrm{~s}$ ) with $20 \mathrm{~s}$ passive rest and then $60 \mathrm{~s}$ cool down continuous passive motions.

Shoulder joint muscle strength testing. Shoulder joint flexion and extension testing was performed in supine position, upper extremity straight, $10^{\circ}$ flexing in elbow joint is acceptable, $90^{\circ}$ angle in shoulder joint. Shoulder joint adduction and abduction was performed in supine position, upper extremity straight, $10^{\circ}$ flexing in elbow joint is acceptable, $60^{\circ}$ angle in shoulder joint. Shoulder joint internal and external rotation testing was carried out in sitting position, elbow joint in $90^{\circ}$ flexion and $60-75^{\circ}$ abduction, $25^{\circ}$ angle in shoulder joint.

Elbow joint testing. Elbow joint flexion and extension was tested in sitting position with $90^{\circ}$ in elbow joint, wrist was in supination position during flexion and in pronation position during extension exercise.

Wrist joint testing. Wrist flexion and extension was performed in sitting position with $60-70^{\circ}$ flexion in elbow joint and $50^{\circ}$ in wrist joint. Forearm pronation and supination performed in sitting position, a rotation axis was parallel to forearm, testing angle $-90^{\circ}$.

Hip joint testing. Hip flexion and extension were performed in supine position, testing angle $80^{\circ}$. Hip adduction and abduction testing position was lying on one side with testing angle in hip joint of $45^{\circ}$.

Knee joint testing. Knee flexion and extension were performed in a sitting position, testing angle was $90^{\circ}$.

Ankle joint testing. Ankle joint dorsal flexion and plantar flexion were performed in supine position with knee flexed at $120^{\circ}$, testing angle in joint $15^{\circ}$. Ankle inversion and eversion was 
measured lying on one side, knee slightly bended, testing angle of $45^{\circ}$.

Spine and abdominal muscle testing. Spine flexion and extension exercise was performed in a sitting position, testing angle $-50^{\circ}$.

Verbal and visual feedback was used to increase the motivation of the young tennis players. For data analysis we chose the best result for current player, an exception was the first repetition - if the best record was during the first repetition, we did not take it for the following data analysis - this is based on recommendation of Davies et al. (2000).

\section{RESULTS}

Young tennis players of the same age and qualification that were training in the same group took part in the research. Regardless of these circumstances, indicators of muscle group strength and their mutual relations were different for each participant.

Shoulder joint muscle strength. The measurements show that all participants of the experiment had more powerful shoulder extensors than flexors: right shoulder extensors $39.5 \pm$ $9.9 \mathrm{~N} \cdot \mathrm{m}$ and left $40.6 \pm 9.1 \mathrm{~N} \cdot \mathrm{m}$, right shoulder flexors $29.9 \pm 4.5 \mathrm{~N} \cdot \mathrm{m}$ and left $25.4 \pm 3.0 \mathrm{~N} \cdot \mathrm{m}$. The average result of right shoulder adductors was $24.15 \pm 2.8 \mathrm{~N} \cdot \mathrm{m}$, for abductors $23.15 \pm 4.25 \mathrm{~N} \cdot \mathrm{m}$, but for left shoulder adductors $26.22 \pm 7.2 \mathrm{~N} \cdot \mathrm{m}$ and abductors $22.91 \pm 5.07 \mathrm{~N} \cdot \mathrm{m}$. Muscular pronounced bi-lateral imbalance was observed in shoulder joint internal and external rotators, averages for right shoulder internal rotators $25.91 \pm 3.61 \mathrm{~N} \cdot \mathrm{m}$ and external rotators $16.31 \pm 6.34 \mathrm{~N} \cdot \mathrm{m}$, for left shoulder internal rotators $20.45 \pm 5.88 \mathrm{~N} \cdot \mathrm{m}$ and external rotators $13.02 \pm 4.39 \mathrm{~N} \cdot \mathrm{m}$.

Elbow joint muscle strength. The average group indicator for right elbow joint flexors was $25.34 \pm 3.96 \mathrm{~N} \cdot \mathrm{m}$, for extensors $23.90 \pm 6.99 \mathrm{~N} \cdot \mathrm{m}$ and for left elbow joint flexors was $21.58 \pm 5.82 \mathrm{~N} \cdot \mathrm{m}$, for extensors $26.10 \pm 8.56 \mathrm{~N} \cdot \mathrm{m}$.

Wrist joint muscle strength. The average group indicator of right wrist flexors was $5.33 \pm$ $2.20 \mathrm{~N} \cdot \mathrm{m}$ and extensors $5.14 \pm 1.52 \mathrm{~N} \cdot \mathrm{m}$, for left wrist flexors $8.34 \pm 1.34 \mathrm{~N} \cdot \mathrm{m}$ and extensors $4.01 \pm$ $1.50 \mathrm{~N} \cdot \mathrm{m}$. The analysis of wrist pronators and supinators testing results showed that right wrist pronator strength was $5.56 \pm 1.47 \mathrm{~N} \cdot \mathrm{m}$ and for supinators $4.52 \pm 0.48 \mathrm{~N} \cdot \mathrm{m}$; for left wrist pronators it was $5.96 \pm 1.97 \mathrm{~N} \cdot \mathrm{m}$ and for supinators it was $4.02 \pm 2.37 \mathrm{~N} \cdot \mathrm{m}$.
Hip joint muscles strength. The testing results of hip joint flexors and extensors maximum torque showed that flexors dominated over extensors, the average group torque indicator of right hip flexors was $116.63 \pm 20.69 \mathrm{~N} \cdot \mathrm{m}$ and for extensors it was $73.32 \pm 14.39 \mathrm{~N} \cdot \mathrm{m}$, for left hip flexors $128.64 \pm$ $25.86 \mathrm{~N} \cdot \mathrm{m}$ and for extensors $81.22 \pm 11.49 \mathrm{~N} \cdot \mathrm{m}$. Adductors of hip joint muscles were more powerful than abductors, right hip adductors torque average indicator was $77.46 \pm 15.09 \mathrm{~N} \cdot \mathrm{m}$, for abductors $66.39 \pm 7.62 \mathrm{~N} \cdot \mathrm{m}$ and for left hip adductors $76.63 \pm$ $14.15 \mathrm{~N} \cdot \mathrm{m}$, for abductors $65.41 \pm 10.14 \mathrm{~N} \cdot \mathrm{m}$.

Knee joint muscles strength. Right knee flexors torque was $131.58 \pm 26.67 \mathrm{~N} \cdot \mathrm{m}$, extensors $50.74 \pm 6.04 \mathrm{~N} \cdot \mathrm{m}$ and for left knee joint muscles respectively flexors $130.00 \pm 28.00 \mathrm{~N} \cdot \mathrm{m}$ and extensors $54.65 \pm 12.67 \mathrm{~N} \cdot \mathrm{m}$.

Ankle joint strength. The average indicators of the group for right ankle dorsal flexors was $80.02 \pm$ $30.52 \mathrm{~N} \cdot \mathrm{m}$, plantar flexors $33.04 \pm 6.97 \mathrm{~N} \cdot \mathrm{m}$ and for left ankle dorsal flexors $83.40 \pm 19.60 \mathrm{~N} \cdot \mathrm{m}$, planar flexors $30.64 \pm 8.00 \mathrm{~N} \cdot \mathrm{m}$. The average torque of group right ankle invertors was $18.52 \pm 4.05 \mathrm{~N} \cdot \mathrm{m}$, evertors $15.66 \pm 2.97 \mathrm{~N} \cdot \mathrm{m}$ and left foot respectively invertors $19.42 \pm 4.38 \mathrm{Nm}$ and evertors $14.23 \pm$ $2.57 \mathrm{~N} \cdot \mathrm{m}$.

Spine and abdominal muscle strength. There was the same tendency for all young tennis players - domination of spine extensors back muscles. The average indicators of maximum torque of abdominal muscles spine flexors were $94.47 \pm 12.30 \mathrm{~N} \cdot \mathrm{m}$ and of extensors $185.40 \pm$ $34.35 \mathrm{~N} \cdot \mathrm{m}$ respectively.

\section{DISCUSSION}

The main idea for investigating muscle strength topography is to understand the muscle strength condition of tennis specific and non-specific muscles, to find out critical level of muscle strength ratio and imbalance. The present study focused on the 11-year-old competitive tennis players - girls. Muscle strength topography of young tennis player reflects the functional state of different muscles at 11 years of age and the influence of tennis specific training. To be able to acquire and to perform stroke technique, it is important to have a specific muscle strength development level (Saccol et al., 2010) and this is the reason why during the training of young tennis players a particular attention $(60-70 \%$ of all training time) needs to be paid to musculoskeletal system strengthening (Schönborn, 1998; Zuša, 
2013) and promotion of all muscle group strength development.

There are limited resources on the subject of young tennis player muscle strength measuring. Strength deficits or muscle imbalance is assumed as one of several injury risk factors in sport (Alizadehkhaiyat et al., 2007; Almekinders \& Temple, 1998). It has been suggested that the incidence of various types of overuse injuries may be reduced by performance of sport and motor-specific resistance training, potentially after measuring agonist and antagonist strength imbalances to identify any predisposition for injury (Alizadehkhaiyat et al., 2007; Ellenbecker, Roetert \& Riewald, 2006; Fleck \& Falkel, 1986), especially in young tennis players - injuries can involve virtually all anatomical regions of the body (Ellenbecker, 2014). It has been verified that during a period of 11-12 years children's physiological features do not show much muscle strength increase (Burnie, 1987; Degache, Richard, Edouard, Oullion, \& Calmes, 2010; Gur, Akova, Punduk, \& Kucucoglu, 1999; Sunnegardh, Bratteby, Nordesjo, \& Nordgren, 1998). This fact allows us to assume that increase of the muscle strength could be connected with performing a regular physical exercise and tennis practice influence (Chandler, Kibler, Stracener, Zeigler, \& Pace, 1992; Saccol et al., 2010; Zuša, Lanka, \& Čupriks, 2012).

Upper extremity muscle strength, level of bi-lateral and contra-lateral imbalance. The role of upper extremity (shoulder, elbow and wrist joint) muscles during forehand stroke production has been studied by Bahamonde and Knudson (2003). Over-training, repetitive movements (Ellenbecker et al., 2006), training errors, poor and faulty stroke technique, inappropriate equipment or the level of expertise (Hayot et al., 2014), flexibility problems, poor circulation, strength deficit or muscle imbalance (Almekinders, \& Temple, 1998) could progress such injury as swimmers' shoulder, lateral epicondylitis, lateral tendinosis, lateral epicondylopathy, tennis elbow, radial epicondylalgia, extensor tendinopathy and row elbow pain (Alizadehkhaiyat et al., 2007). A shoulder-elbow-wrist segment cooperation is very significant in tennis stroke production, a weak muscle of one joint will affect next segment, for example, a weakness of shoulder muscles will provide elbow muscle overuse because of compensation action, etc.
There are several studies (Chandler et al, 1992; Ellenbecker, 1992; Julienne, Gauthier, Moussay, \& Davenne, 2007; Yildiz, Aydin, Kirapl, Hazneci, \& Kalyon, 2006;) which showed that competitive tennis players had upper extremity contra-lateral imbalance - dominant arm muscles are better developed in a comparison with nondominant arm muscles. Shoulder internal / external rotators and adductors/abductors are often studied in tennis players, because these muscles are assumed as tennis specific - they play an important role in racquet acceleration in all tennis strokes (Bahamonde \& Knudson, 2003; Julienne, Gauthier, \& Davenne, 2012; Ryu, McCormick, Jobe, Moynes, \& Antonelli, 1988; Saccol et al., 2010). All studies have similar results - tennis players have a significant contra-lateral imbalance in shoulder internal rotators (Chandler et al., 1992; Ellenbecker \& Roetert, 2003; Ellenbecker, 1992; Nagel \& Avram, 2013), this is assumed to be related with the tennis training demands and it is considered as an adaptation to the serving motion. The ratio values recommended to provide muscular balance are between $66-75 \%$, such that shoulder external rotators are at least $2 / 3$ the strength of the shoulder internal rotators in the concentric mode (Saccol et al., 2010), a conventional strength ratio of 2:3-3:4 (0.66-0.75) to prevent shoulder injuries (Ellenbecker, \& Davies, 2000). The results of our study approved previous study trends - young tennis players have contra-lateral imbalance in shoulder internal rotators, which varied between $22-42 \%$ (only for one participant bi-lateral imbalance level was only $12 \%$ ). In shoulder external rotators for 3 participants the level of contra-lateral imbalance was not higher than $11 \%$ and for other 3 - it varied between $44-52 \%$. Contra-lateral imbalance in shoulder adductors was found for 3 participants $(22-36 \%)$ and in flexors for 1 participant $(36 \%)$. Level of bi-lateral imbalance highly varied between all participants: difference in internal and external rotators for right shoulder was $10-75 \%$, for left shoulder $15-56 \%$; in adductors and abductors for right shoulder $0-28 \%$, for left shoulder $0-25 \%$; in shoulder extensors and flexors for right $11-38 \%$ and for left $23-50 \%$. Including a specific strength training program in tennis practice to avoid shoulder muscle strength imbalance proved a positive effect (Julienne et al., 2012; Niederbracht, Shim, Sloniger, PaternostroBayles, \& Short, 2008). 
Lack of elbow joint muscle strength or muscle strength imbalance could affect racquet orientation during stroke production (this will affect accuracy and efficiency of the stroke) and could be an injury predisposition (Bazzucchi, Riccio, \& Felici, 2008; Elliott, 2003). Greater dominant arm strength in elbow extensors was found in junior elite tennis players (Ellenbecker, \& Roetert, 2002). The results of our study showed that the trend of imbalance between elbow flexors and extensors was different for all participants, 2 participants had bi-lateral imbalance 21 and $31 \%$ of flexors dominance for right elbow joint; and 2 participants had bi-lateral imbalance $15,27 \%$ of flexors dominance and 3 had $13,32,56 \%$ of extensors dominance for left joint. Level of contra-lateral imbalance varied between $13-64 \%$ for elbow flexors and between 9-74\% for extensors. The data of the testing young tennis players differed from other similar studies (Bazzucchi et al., 2008; Howatson, \& Someren, 2005) - indicators of young tennis players elbow flexors and extensors maximal torque are significantly lower and it could be explained with age differences of the participants.

Wrist is distal segment in tennis stroke upper extremity kinematic chain, tennis specialists named wrist as weakest part, because very often wrist muscle strength training stays behind physical condition training. During prolonged practice, repetitive high level of finger/wrist extensor muscle solicitations in all tennis strokes could provoke the overuse of these muscles and affect the tendinous tissue of their origins in the most extreme cases (Hayot et al., 2014). In similar study Salonikidis et al. (2009) measured WrF strength in adult high level tennis players $(n=6)$, handball players $(n=4)$ and University students $(\mathrm{n}=10)$. Salonikidis et al. (2009) concluded that there was a high level of individual variation in the groups and maximal difference between groups muscle strength torque wasn't significant $(p>.05)$. This proves that regular practice of tennis and handball doe not influence on wrist flexors strength development and to improve muscle strength it is necessary to perform specific exercises. Alizadehkhaiyat et al. (2007) and Hayot et al. (2014) found that wrist flexors were stronger than wrist extensors in healthy adults. Significantly greater dominant arm wrist flexors and extensors, as well as forearm pronation strength was found in highly skilled adult tennis players by Ellenbecker (1991). In our study the results of maximal torque in wrist flexors/extensors and pronators/supinators were low (in comparison with adult participants in other studies) and similar between each other. Significant trend for all participants was that wrist pronators were stronger than supinators: bi-lateral imbalance for right wrist joint varied between $8-29 \%$ and for left wrist joint $-25-73 \%$. This fact could be explained with groundstroke, smash and serve stroke technique biomechanics - in finish part of ball follow-through phase the input of wrist pronators are essential. We found contra-lateral imbalance in wrist flexors, extensors, pronators and supinators - dominant arm muscles were stronger, this fact confirms previous researches data (Ellenbecker et al., 2006).

Low extremity muscle strength, level of bilateral and contra-lateral imbalance. There are certain opinions (Chow, Park, \& Tilman, 2009; Ellenbecker \& Roetert, 1995) that lower body part development in tennis players is as important as upper part physical development. The proper foot work provides enough quick stars, competent speed during running and start/stop movements (Ellenbecker et al., 2009). From biomechanical point of view strength of the muscles of the low body parts plays an important role in powerful stroke production (Elliott, 2006; Kopsic Segal, 2003; Zusa, 2013). All movements in tennis are initiated by the feet pushing against the ground, and a force and momentum transfer via the kinetic chain segments of the lower extremities to the trunk, upper extremities and, finally, the racquet. Tennis requires repetitive multidirectional movement patterns that can lead to lower extremity injury (Ellenbecker et al., 2007).

Young tennis players' hip joint muscle strength results showed, that level of extensors/ flexors bi-lateral imbalance for right joint was between $19-45 \%$ and for left between $21-51 \%$ hip extensors dominance; contra-lateral imbalance for 4 participants was between $10-24 \%$ (left hip joint extensor and flexor muscles dominate on right hip joint muscle). For 3 participants, hip adductors were stronger than abductors - level of bi-lateral imbalance $16-36 \%$ for right side and between 14 $36 \%$ for left side muscles, contra-lateral imbalance was not significant for hip adductors and abductors.

We found a significant difference in knee joint muscle strength indicators. For all participants, knee extensors were stronger than flexors: a level of bilateral imbalance for right leg was $51-65 \%$ 
and for left leg 50-67\%. Level of contra-lateral imbalance in these muscles was not significant less than $14 \%$ for flexors and less than $24 \%$ for extensors. This data verifies previous researches - no significant difference exists between the dominant and non-dominant lower extremity for knee extensors and flexors strength in elite junior tennis players (Ellenbecker et al., 2007; Ellenbecker \& Roetert, 1995) and adult tennis players (Read \& Bellamy, 1990).

Ankle joint is assumed as weakest part in low extremity kinematic chain, proper throwlike movement production begins from ground reaction forces (Bartonietz, 2000; Lanka, 2000; Elliott, 2006; Ivancevic, Jovanovic, Djukic, \& Lukman, 2011; Kopsic Segal, 2003) and ankle joint muscle strength here is vital as much, as during speed on-court movements and from injury prevention point of view. The results of our study showed the same trend for all participants ankle dorsal flexors strength torque was bigger than plantar flexors, level of bi-lateral imbalance was between $31-66 \%$ for right foot and $54-70 \%$ for left foot. The results are in a conflict with Morrison \& Kaminski's (2007) study - ankle plantar flexors were stronger than dorsal flexors for physical active adults (man $\mathrm{n}=8$, woman $\mathrm{n}=18$ ) and all plantar and dorsal flexors indicators for adults were much higher in comparison with our results, this could be explained with age difference of the participants. Ankle evertor and invertor indicators and level of bi-lateral and contra-lateral imbalance highly varied between all study participants.

Spine and abdominal muscle strength condition in different participants is a wellstudied question among the researchers. Once of the motions that can particularly stress the spine in tennis players is the combined movements of extension, lateral flexion and rotation that are inherent in the loading phase of the tennis serve (Ellenbecker et al., 2009). Everett et al. (2008) and Sanchis-Moysi, Idoate, Dorade, Alayon and Calbet (2010) measured spine flexors and extensors in adult tennis players, runners, swimmers and nonathletes. The main conclusion of these two studies (Everett, Strutton, \& McGregor, 2008; SanchisMoysi et al., 2010) was similar - abdominal muscles were significantly stronger than spine muscles in adult tennis players and spine extensors were stronger in non-athletes (Sanchis-Moysi et al., 2010). Similar results of spine flexors dominance for tennis players showed other specialists (Andersson, Swart, \& Thrstensson, 1988; Roetert, McCormick, \& Ellenbecker, 1996) who explained this with tennis technique specifics. Our study results are in conflict with previous mentioned - young tennis players' spine extensors were significantly stronger than flexors - the level of bi-lateral imbalance was between 42 and 55\% for all participants. Our explanation could be only that, possibly, at the age of 11 the tennis specific topography in accordance of spine and abdominal muscle strength indicators has not developed yet, tennis player specific spine flexors dominance could be a result of the influence of several years training.

The data presented in this research provides descriptive muscle strength topography of 11-yearold tennis players. The main limitations of the study were a small number of participants, only girls, not tested body core rotator muscles, which plays an important role in powerful stroke generation.

\section{CONCLUSIONS}

1. The study pointed out that, in order to develop tennis specific muscle strength topography, young tennis players should train spine flexors, shoulder adductors, internal rotators and wrist pronators more.

2. To avoid the increase of muscle bi-lateral imbalance it is highly recommended to pay more attention to shoulder abductors and external rotators, elbow flexors and extensors (especially for the right hand), wrist supinators and extensors, knee extensors and ankle joint plantar flexors.

3. For contra-lateral imbalance, prevention in addition to work with non-dominant upper extremity muscles should be considered for shoulder joint internal and external rotators, wrist supinators.

4. It is highly recommended for 11-year-old tennis players to complete tennis practice with muscle strength development exercises and special musculoskeletal system strengthening programs - it could play a key role in injury prevention in young tennis players.

Acknowledgement. This study was part of the research which was financially supported by ESF project "Atbalsts sporta zinātnei" Nr. 2009/0155/1DP/1.1.2.1.2/09/IPIA/VIAA/010. 


\section{REFERENCES}

Alizadehkhaiyat, O., Fisher, A. C., Kemp, G. J., \& Frostick, S. P. (2007). Strength and fatigability of selected muscles in upper limb: Assessing muscle imbalance relevant to tennis elbow. Journal of Electromyography and Kinesiology, 17, 428-436. doi: http://dx.doi. org/10.1016/j.jelekin.2006.04.007

Almekinders, L. C., \& Temple, J. D. (1998). Etiology, diagnosis and treatment of tendonitis: An analysis of the literature. Medicine \& Science in Sport \& Exercise, 30, 1183-1190.

Andersson, E., Swart, L., \& Thrstensson, A. (1988). Trunk muscle strength in athletics. Medicine Science in Sport Exercise, 20, 587-593.

Andrade, M. S., Barbosa de Lira, C. A., Vancini, R. L., Almeida, A. A., Benedito-Silva, A. A., \& Silva, A. C. (2013) Profiling the isokinetic shoulder rotator muscle strength in 13- to 36-year-old male and female handball players. Physical Therapy in Sport, 14, 246-252. http:// dx.doi.org/10.1016/j.ptsp.2012.12.002

Bahamonde, R. E., \& Knudson, D. (2003). Kinetics of the upper extremity in the open and square stance forehand. Journal of Science and Medicine in Sport, 6(1), 88-101.

Bartonietz, K. (1994) Training, technique and specific power in throwing events. Modern Athlete and Coach, 32(1), 1-16.

Bartonietz, K. (2000). Javelin throwing: An approach to performance. In Vardo raidè. Zatsiorsky (Ed.), Biomechanics in Sport: Performance Enhancement and Injury Prevention (pp. 401-434). Oxford: Blackwell Science Ltd.

Bazzucchi, I., Riccio, M. E., \& Felici, F. (2008). Tennis players show a lower coactivation of the elbow antagonist muscles during isokinetic exercises. Journal of Electromyography and Kinesiology, 18, 752-759.

Burnie, J. (1987). Factors affecting selected reciprocal muscle group ratios in preadolescents. International Journal of Sports Medicine, 8(1), 40-45.

Chandler, T. J., Kibler, W. B., Stracener, E. C., Zeigler, A. K., \& Pace, B. (1992). Shoulder strength, power and endurance in college tennis players. American Journal of Sports Medicine, 20, 455-458.

Chow, J. W., Park, S. A., \& Tilman, M. D. (2009). Lower trunk kinematics and muscle activity during different types of tennis serves. Sports Medicine Arthroscopy Rehabilitation Therapy \& Technology, 1, 24. doi:10.1186/1758-2555-1-24

Christmass, M. A., Richmond, S. E., Cable, N. T., \& Arthur, P. G. (1998). Straipsnis? Journal of Sports Science, 16, 739-747.

Clements, A. S., Ginn, K. A., \& Henley, E. (2000) Correlation between muscles strength and throwing speed in adolescent baseball players. Physical Therapy in Sport, 2, 4-14.

Davies, G. J., Ellenbecker, T. S. \& Brinks, A. (2000). Test interpretation. In Lee, E. Brown (Ed.), Isokinetic in Human Performance (pp. 3-24). Human Kinetics, Florida Atlantic University.
Degache, F., Richard, R., Edouard, P., Oullion, R., Calmels, P. (2010). The relationship between muscle strength and physiological age: A cross-sectional study in boys aged from 11 to 15. Manuals of Physical and Rehabilitation Medicine, 53, 180-188.

Ellenbecker, T. S. (1991). A total arm strength isokinetic profile of highly skilled tennis players. Isokinetic Exercise Science, 1, 9-21.

Ellenbecker, T. S., \& Davies, G. J. (2000). The application of isokinetics in testing and rehabilitation of the shoulder complex. Journal of Athletic Training, 35, 338-350.

Ellenbecker, T. S. (2014). Musculo-skeletal examination of elite junior tennis players. ASPETAR Sports Medicine Journal, 3, 548-556.

Ellenbecker, T. S., Pluim, B., Vivier, S., \& Sniteman, C. (2009). Common injuries in tennis players: exercises to address muscular imbalances and reduce injury risk. Strength and Conditioning Journal, 31(4), 50-58.

Ellenbecker, T. S., \& Roetert, E. P. (2003). Age specific isokinetic glenohumeral internal and external rotation strength in elite junior players. Journal of Science and Medicine in Sport, 6, 65-72.

Ellenbecker, T. S., \& Roetert, E. P. (1995). Concentric isokinetic quadriceps and hamstring strength in elite junior tennis players. Isokinetic Exercise Science, 5, 3-6. Ellenbecker, T. S., \& Roetert, E. P. (2002) Isokinetic profile of elbow flexion and extension strength in elite junior tennis players. Journal of Orthopedics \& Sports Physical Therapy, 33, 79-84.

Ellenbecker, T. S., Roetert, E. P., \& Riewald, S. (2006). Isokinetic profile of wrist and forearm strength in elite female junior tennis player. British Journal Sports Medicine, 40, 411-414.

Ellenbecker, T. S., Roetert, E. P., Sueyoshi, T., \& Riewald, S. (2007). A descriptive profile of age-specific knee extension flexion strength in elite junior tennis players. British Journal of Sports Medicine, 41, 728-732.

Ellenbecker, T. S. (1992). Shoulder internal and external rotation strength and range of motion of highly skilled tennis players. Isokinetic Exercise Science, 2, 1-8.

Elliott, B. (2006). Biomechanics and tennis. British Journal of Sports Medicine, 40, 392-396.

Elliott, B. (2003). The development of racquet speed. In Biomechanics of advanced tennis (pp. 33-47). ITF Ltd.

Everett, R., Strutton, P. H., \& McGregor, A. H. (2008). Do asymmetries exist in trunk muscles and is this influenced by sporting task? Isokinetic and Exercise Science, 16, 255-262.

Fleck, S. J., \& Falkel, J. E. (1986). Value of resistance training for the reduction of sports injuries. Sports Medicine, 3, 61-68.

Girard, O. \& Millet, G. P. (2008). Neuromuscular fatigue in racquet sports. Neurologic Clinics, 26, 181-194.

Gur, H., Akova, B., Punduk, Z., \& Kucucoglu, S. (1999). Effects of age on the reciprocal peak torque ratios during knee muscle contractions in elite soccer players. 
Scandinavian Journal of Medicine \& Science in Sports, 9, 81-87.

Hay, J. G. (1992). Mechanical basis of strength expression. In P. Komi (Ed.), Strength and Power in Sport (pp. 197-207). Oxford: Blackwell Science,

Hayot, C., Vigouroux L., Rossi, J. Goislard de Monsabert, B., Barla, C., \& Berton, E. (2014) Measurements of tennis players' forearm muscle force imbalance to assess the potential risk of lateral epicondylitis. Procedia Engineering, 72, 174-179.

Henry, F. M. (1960) Relationship between individual differences in strength and mass in the arm movement. The Research Quarterly, 31(1), 24-31.

Howatson, G., \& Someren, K. A. (2005). The reproducibility of peak isometric torque and electromyography activity in unfamiliarised subjects using isokinetic dynamometry on repeated days. Isokinetics and Exercise Science, 13, 103-109.

Ivancevic, T., Jovanovic, B., Jovanovic, S., Djukic, \& M, Lukman, A. (2011). Paradigm shift for future tennis. Berlin: Springer.

Julienne, R., Gauthier, A., \& Davenne, D. (2012). Fatigueresistance of the internal rotator muscles in the tennis player's shoulder: Isokinetic and electromyographic analysis. Physical Therapy in Sport, 13, 22-26.

Julienne, R., Gauthier, A., Moussay, S., \& Davenne, D. (2007). Isokinetic and electromyographic study of internal and external rotator muscles of tennis player. Isokinetic and Exercise Science, 15, 173-182.

Kopsic Segal, D. (2003). Tennis biodynamic system. Buenos Aires: Indugraf SA.

Kovacs, M. S. (2006). Applied physiology of tennis performance. British Journal Sports Medicine, 40, 381-386.

Lanka, J. (2000). Shot putting. In Vardo raidè. Zatsiorsky (Ed.), Biomechanics in sport: Performance enhancement and injury prevention (pp. 435-457). Oxford: Blackwell Science Ltd.

Mendez-Villanueva, A., Fernandez-Fernandez, J., Bishop, D., Fernandez-Garcia, B., \& Terrados, N. (2007). Activity patterns, blood lactate concentrations and ratings of perceived exertion during a professional singles tennis tournament. British Journal of Sports Medicine, 41, 296-300.

Morrison, K. E., \& Kaminski, T. W. (2007). The reproducibility of an isokinetic testing technique at the ankle joint. Isokinetic and Exercise Science, 15, 245-251.

Nagel, A., \& Avram, C. (2013). Reference values and gender differences of the functional parameters in Romanian elite junior tennis players. Timisoara Physical Education and Rehabilitation Journal, 5(10), 22-27.

Niederbracht, Y., Shim, A. L., Sloniger, M. A., Paternostro-Bayles, M., Short, T. H. (2008). Effect of shoulder injury prevention strength training program on eccentric external rotator muscle strength and glenohumeral joint imbalance in female overhead activity athletes. The Journal of Strength and Conditioning Research, 22, 140-145.
Read, M. T. F., \& Bellamy, M. J. (1990). Comparison of hamstring/quadriceps isokinetic strength ratios and power in tennis, squash, and track athletes. British Journal Sports Medicine, 24, 178-182.

Reid, M., \& Schneiker, K. (2008). Strength and conditioning in tennis: Current research and practice. Science and Medicine in Sport, 11, 248-256.

Roetert, E. P., McCormick, S. W. B., \& Ellenbecker, T. S. (1996). Relationship between isokinetic and functional trunk strength in elite junior tennis players. Isokinetics and Exercise Science, 6, 15-30.

Ryu, R. K., McCormick, J., Jobe, F. W., Moynes, D. R., \& Antonelli, D. J. (1988). An electromyographic analysis of shoulder function in tennis player. American Journal of Sports Medicine, 16, 481-485.

Saccol, M. F., Gracitelli, G. C., Teixeira da Silva, R., Laurino, C. F. S, Fleury, A. M., Andrade, M. S., \& Carlos da Silva, A. (2010). Shoulder functional ratio in elite junior tennis players. Physical Therapy in Sport, 11, 8-11.

Salonikidis, K., Amiridis, I. G., Oxyzoglou, N., Saez de Villareal, E. S., Zafeiridis, A., \& Kellis, E. (2009). Force variability during isometric wrist flexion in highly skilled and sedentary individuals. European Journal of Applied Physiology, 107, 249-254.

Sanchis-Moysi, J., Idoate, F., Dorade, C., Alayon, S., \& Calbet, J. A. L. (2010). Large asymmetric hypertrophy of rectus abdominis muscle in professional tennis players. PLOS ONE, 5(12), 1-9.

Schönborn, R. (1998). Tennis techniktraining. Germany: Meyer \& Meyer Sport, Aachen.

Stephenson, D. G., Lamb, G. D., \& Stephenson, G. M. M. (1998). Events of the excitation-contraction-relaxation (E-C-R) cycle in fast and slow twitch mammalian muscle fibres relevant to muscle fatigue. Acta Physiology Scandinavia, 162, 229-245.

Sunnegardh, J., Bratteby, L. E., Nordesjo, L. O., \& Nordgren, B. (1998). Isometric and isokinetic muscle strength, anthropometry and physical activity in 8- and 13-years-old children. European Journal of Applied Physiology, 58, 291-297.

Ulbricht, A., Fernandez-Fernandez, J., \& Ferrauti, A. (2013). Conception for fitness testing and individualized training programs in the German tennis federation. Sports Orthopaedics and Traumatology, 29(3), 180-192. Yildiz, Y., Aydin, T., Kiralp, M. Z., Hazneci, B., Kalyon, T. A. (2006). Shoulder terminal range eccentric antagonist / concentric agonist strength ratios in overhead athletes. Scandinavian Journal of Medicine and Science in Sports, 16, 174-180.

Zuša, A. (2013). Dažādas kvalifikācijas tenisistu labā sitiena biomehānika un jauno spēlètāju mioskeletālās sistēmas izpēte (Unpublished doctoral dissertation). Riga: Latvian Academy of Sport Education.

Zuša, A., Lanka, J., \& Čupriks L. (2012). Glenohumeral joint muscle strength of the young tennis players. Journal of Human Sport and Exercise, 7(1), 8-16. 